\title{
Impacts of deforestation and afforestation in the Mediterranean region as simulated by the MPI atmospheric GCM
}

\author{
Lydia Dümenil Gates ${ }^{\text {a,b, * }}$, Stefan Ließ ${ }^{\text {a }}$

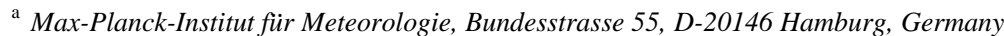 \\ ${ }^{\mathrm{b}}$ Center for Ocean-Land-Atmosphere Studies, 4041 Powder Mill Road, Calverton, MD 20705, USA
}

Received 21 December 1999; received in revised form 15 October 2000; accepted 26 October 2000

\begin{abstract}
For two reasons it is important to study the sensitivity of the global climate to changes in the vegetation cover over land. First, in the real world, changes in the vegetation cover may have regional and global implications. Second, in numerical simulations, the sensitivity of the simulated climate may depend on the specific parameterization schemes employed in the model and on the model's large-scale systematic errors. The Max-Planck-Institute's global general circulation model ECHAM4 has been used to study the sensitivity of the local and global climate during a full annual cycle to deforestation and afforestation in the Mediterranean region. The deforestation represents an extreme desertification scenario for this region. The changes in the afforestation experiment are based on the pattern of the vegetation cover 2000 years before present when the climate in the Mediterranean was more humid. The comparison of the deforestation integration to the control shows a slight cooling at the surface and reduced precipitation during the summer as a result of less evapotranspiration of plants and less evaporation from the assumption of eroded soils. There is no significant signal during the winter season due to the stronger influence of the mid-latitude baroclinic disturbances. In general, the results of the afforestation experiment are opposite to those of the deforestation case. A significant response was found in the vicinity of grid points where the land surface characteristics were modified. The response in the Sahara in the afforestation experiment is in agreement with the results from other general circulation model studies. (C) 2001 Elsevier Science B.V. All rights reserved.
\end{abstract}

Keywords: climate; climate change; deforestation; afforestation

\section{Introduction}

Only recently have the impacts of land-use change on the overlying atmosphere been measured in a systematic way in field experiments. The experience from a measurement campaign that covered an Ama-

\footnotetext{
* Corresponding author. Lawrence Berkeley National Laboratory, 1 Cyclotron Road, Mailstop 90-1116, Berkeley, CA 94720 , USA. Tel.: +1-510-486-6642; fax: +1-510-486-5686.

E-mail address: LGates@lbl.gov (L. Dümenil Gates).
}

zonian forest area and a forest clearance is summarized by Gash et al. (1996), while the climate in the Mediterranean has been extensively studied in field experiments described by Bolle et al. (1993). For some land-use scenarios, field experiments would be impossible to do-e.g. for future projections of landuse and for future potential changes due to projected anthropogenic climate changes due to the increased so-called greenhouse effect. The effects of such landuse or vegetation change scenarios, however, can be tested in numerical simulations, which describe the 
physical relationships between the atmosphere, the land surface and ocean components of the climate system. Models might also be used to establish the possible impact of historical land use changes. Usually, the vegetation distribution over the continents represents present-day conditions, but these boundary conditions may be changed to represent different surface or vegetation types and their associated physical effects. Potential resulting impacts from vegetation changes include changes in the radiation budget via the surface albedo and changes in the hydrological cycle in terms of evaporation, precipitation, runoff from infiltration excess and drainage, as well as possible interactions with the carbon cycle. The strength and regional variation of such impacts, however, depends on the general architecture and sensitivity of the atmospheric model that is used. In this study, we shall use the Max-Planck-Institute's atmosphere general circulation model ECHAM4 (Roeckner et al., 1996) to simulate the response to specified land-use changes in the Mediterranean region.

The climate of the Mediterranean region in southern Europe and northern Africa is characterized by mild wet winters and warm dry summers. The boundaries of the Mediterranean region are conveniently defined as the area where the climate allows olive trees to grow (Rother, 1993), the northern border of which is approximately given by the $5^{\circ} \mathrm{C}$ January isotherm. In the south, the area is limited to the coastal parts of North Africa. The dominant circulation features of this region are the mid-latitude westerlies in winter, and in summer, the subtropical high-pressure belt associated with the seasonal shift of the inter-tropical convergence zone (ITCZ). The change between the two regimes occurs relatively quickly, so that the spring and autumn seasons are not pronounced. The Mediterranean region is generally shielded from storms from the Atlantic as it is surrounded by mountain ranges. As a consequence, in the summer, this region is sensitive to local changes via interactions with the surface.

In the Mediterranean, the precipitation is important for the maintenance of vegetation. A mean precipitation of about $1 \mathrm{~mm} /$ day during the summer season is required to maintain the Mediterranean forests (Reale and Shukla, 2000), and a reduction in the precipitation pattern due to climate change may lead to the destruction of these forests. On the other hand, reduction of the vegetation cover due to land use changes may affect the local recycling of water by evaporation and lead to less precipitation in the dry season, again resulting in a decrease of vegetation. If there is more precipitation in the rainy season, this would have the additional effect of enhancing the fluvial erosion.

The natural distribution of vegetation types in a region should be in equilibrium with the climate, water and nutrient limitations, but the distribution of vegetation has often been modified by anthropogenic influences. In the Mediterranean region, deforestation has been common practice for more than 2000 years and its impacts are widespread, while deforestation and afforestation scenarios are being discussed for the future. We should note, however, that the influence of a given change in boundary conditions depends crucially on the local climate, and has to be expected to be different in mid-latitudes and in the tropics or subtropics. Thus, the physical description of the impacts of vegetation change in different parts of the world is not transferable, because different threshold values are involved. Vegetation-atmosphere interaction has also been studied in paleoclimate systems.

Several scientific questions arise in this context. The first question is how far regional and local climate change (e.g. due to land use change) will affect the global circulation patterns, or whether they will have only a local impact. This question can only be addressed by global general circulation models. Detailed regional changes can then be estimated from regional models. The second question arises from the hypothesis of a more pluvial climate in Roman times as discussed by Reale and Dirmeyer (2000). Has the historical anthropogenic deforestation in the region lead to a desertification, or do we have to consider other sources of atmospheric variability? If this question is studied with a general circulation model, however, there are uncertainties because of the coarseness of its horizontal resolution at which the relevant equations are solved and due to the assumptions on which the parametrizations of physical processes that are represented by the model are based. For each general circulation model, the sensitivity to certain changes needs to be established. A third question concerns the future conditions. Esti- 
mates of the expected change in global mean temperature associated with an increase of the effects of large-scale global patterns of the anthropogenic emission of so-called greenhouse gases and aerosols are reported to affect the hydrological cycle and heat balance of the region (IPCC, 1990, 1995). This can be viewed as a large-scale global climate change having consequences for the regional climate. Such a climate change is expected to cause higher temperatures and changed availability of water, which may lead to an increase or decrease of the vegetation cover. Any such changes affecting the vegetation cover may feedback on the atmosphere and may lead to an enhancement or diminuition of the original changes. Modifications of vegetation patterns in the past may already have interfered with temperature changes caused by other anthropogenic influences.

In this study, we shall focus on the first two questions. A control simulation with the MaxPlanck-Institute's ECHAM4 atmosphere general circulation model (GCM) (Roeckner et al., 1996) for present-day climate is the basis for two sensitivity studies, one for a deforestation and one for an afforestation scenario. While some of the realism of summer precipitation in terms of the intensity of events is missing in a such coarse resolution GCM, the use of the global model will enable us to see if there are any effects downstream from the area where the local changes are applied and may reveal global teleconnections. Here we shall focus on the quality of the global climate simulation, on the general sensitivity of the ECHAM4 model, and on the consistency of the changes in the simulated hydrological cycle and surface energy budget. A more detailed analysis taking advantage of more realistic levels of internal variability of the higher resolution regional models PROMES and HIRHAM4 is made elsewhere (Polcher et al., 1999).

\section{Description of the model and the sensitivity experiments}

\subsection{The model}

The numerical experiments analysed in this study were performed with the ECHAM4 atmospheric
GCM (Roeckner et al., 1996) at T42 resolution, corresponding to a mesh size of about $2.8^{\circ}$ in longitude and latitude. In the Mediterranean region, this is equal to about $250 \mathrm{~km}$ in the zonal and $300 \mathrm{~km}$ in the meridional directions. The model has 19 vertical levels. The control simulation is a standard integration of 35 years, the first 10 years of which were discarded to eliminate the effects of model spin-up. The experimental simulations then start from 1 January Northern Hemisphere winter conditions of year 11 of this control simulation in order to provide near-saturation at least in northern mid-latitudes. Here, we found that it was sufficient if the first year of the integration was discarded, because after the first year of the integration, the range of the annual cycle of soil moisture fell to within the range of inter-annual variability of the remainder of the simulation. In the control simulation as well as the sensitivity experiments, climatological global sea surface temperatures (SST) averaged over the period 19791988 were used to eliminate interannual variability due to variations in sea surface temperature. The atmospheric variability represented in such integrations is generally less than that in simulations with interannually varying boundary conditions (Bengtsson et al., 1996).

Local Mediterranean SSTs are also prescribed by climatological values. This means that in both the control simulation and the experiments the flow from the land to the sea is unable to modify the sea surface temperature. In the real world, the interaction would cause a warming or cooling by direct heating or upwelling due to the effects of friction, which may also change the water temperature at the surface. Fully coupled ocean models that also include the Mediterranean are currently available at MPI, but limited in horizontal resolution. We restricted this initial series of experiments to prescribed SSTs, because the length of any coupled simulations would have had to be extended considerably in order to statistically interpret the results. The restriction to prescribed SSTs over the Mediterranean Sea, which is always regrettable, however, does not pose a serious problem in this case. The $850 \mathrm{hPa}$ wind field in Fig. 1 shows that the flow over the sea only affects the southeastern part of the area where only few grid points were taken into account in the averaging. 
The parameterization of soil hydrology in ECHAM4 comprises budget equations for the snow amount on the surface, for the water amount intercepted by the vegetation, and for the soil water storage. The time evolution of soil water content considers evaporation, surface runoff and drainage. The runoff scheme (Dümenil and Todini, 1992) takes into account subgrid-scale variations of field capacity over inhomogeneous terrain in a grid-area, and therefore allows runoff even if the bucket type soil reservoir is not fully saturated. Water in the soil water reservoir is accessible for evaporation as a function of the soil water amount and of the vegetation fraction in a grid. Only a maximum value of 10 $\mathrm{cm}$ is accessible for evaporation in the non-vegetated part of a grid point (bare soil). In the vegetated part the difference between actual soil moisture and the wilting point ( $35 \%$ of the maximum soil moisture) is accessible for evaporation.

\subsection{The model control climate}

In the Mediterranean, it is useful to combine the rainy winter months of January, February and March (JFM) and the dry summer months July, August and September (JAS) for averaging. Fig. 1 shows the sea level pressure and $850 \mathrm{hPa}$ wind field for winter and summer in terms of mean values from the ECMWF re-analysis (European Centre for Medium Range Weather Forecasts; Gibson et al., 1997) and the 25-year control simulation. The re-analysis data were calculated at T106 resolution and were later truncated to T42 resolution for optimum comparison with our model results.

Although the quality of the model simulation is generally high during winter deviations from the re-analysis occur in the western Mediterranean, where the Azores high is too strong and extends too far eastward in the control run. (For ECHAM4 there is (a) ECMWF reanolysis JFM: mean sea level pressure $[\mathrm{hPo}$ ]
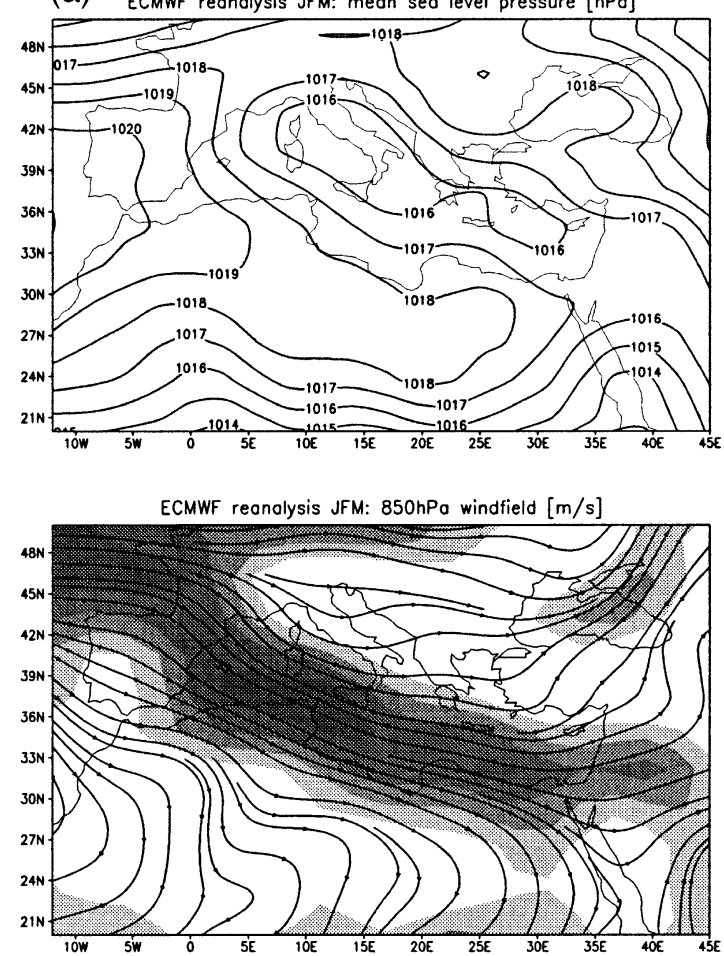
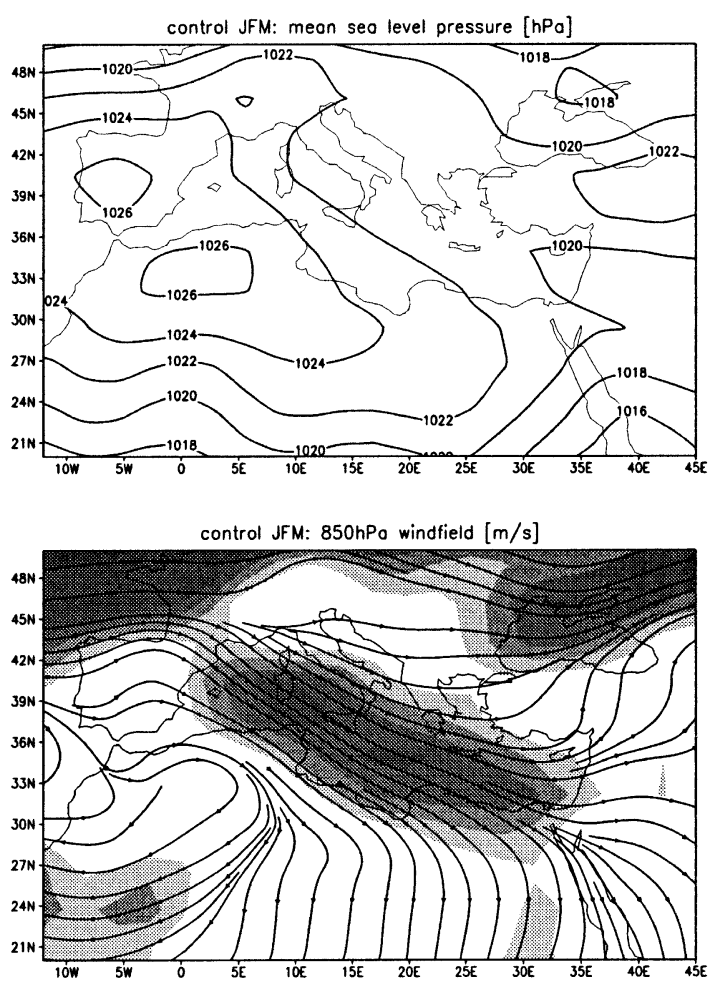

Fig. 1. Mean sea level pressure, $850 \mathrm{hPa}$ wind field and streamlines for the ECMWF reanalysis (1978-1994) (left) and the ECHAM4 25-year control simulation using climatological sea surface temperatures (right) for winter (January/February/March) and summer (July/August/September) averages. 
(b) ECMWF reanalysis JAS: mean seo level pressure [hPo]

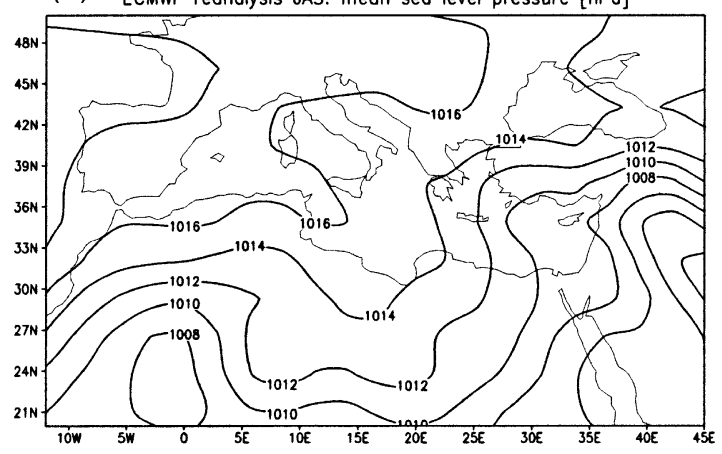

ECMWF reonalysis JAS: $850 \mathrm{hPo}$ windfield $[\mathrm{m} / \mathrm{s}]$

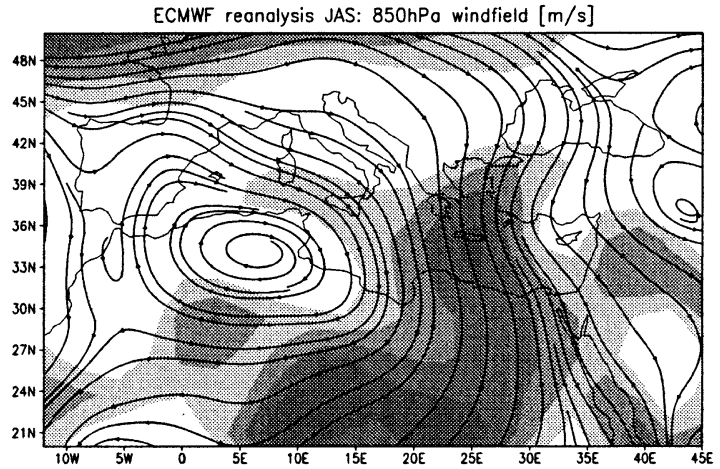

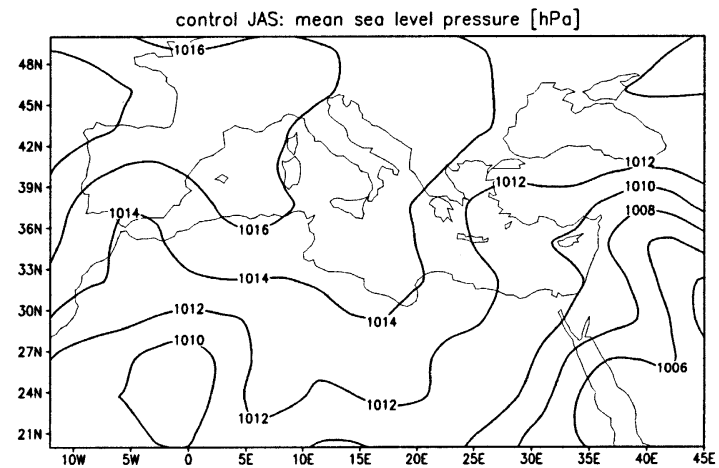

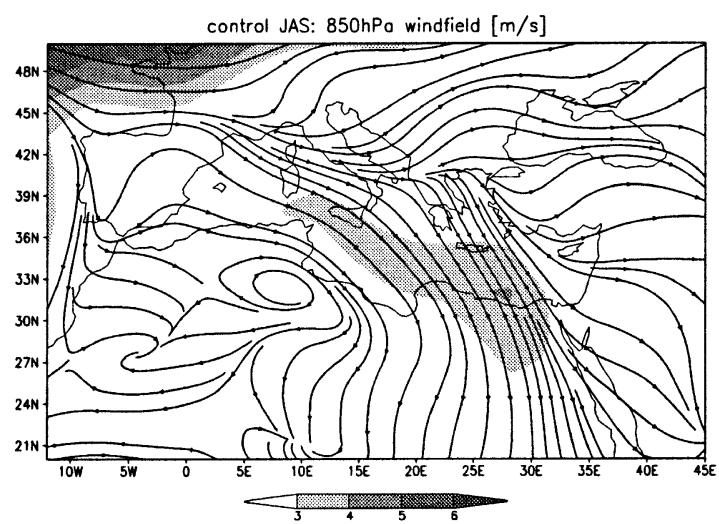

Fig. 1 (continued).

hardly any difference in this region between simulations using interannually varying or climatological SSTs.) This results in a considerable underestimation of precipitation in the western Mediterranean, which also has repercussions for the spring and summer climate, as the soil moisture reservoirs are not replenished. This systematic model error is insensitive to changes in the formulation of the land surface processes and has to be attributed to the model's representation of the general circulation. The sea level pressure in summer is better represented, while the strength of the $850 \mathrm{hPa}$ wind field is underestimated. Precipitation maxima (Fig. 2) are generally underrepresented due to the relatively coarse resolution of the model. The largest precipitation deficiencies occur along the Adriatic coast and near the Caspian Sea. Although our model simulation has a resolution of only T42, there is an indication of rainfall in the Pyrenees in agreement with a higher resolution climatology (Hulme et al., 1995). Precipitation in the Atlas mountain region, however, is much too high in the model simulation.

\subsection{The experiments}

The deforestation experiment simulates the Mediterranean climate after all vegetation in the region that is present today has been removed. In the ECHAM4 model (Roeckner et al., 1996), the horizontal distribution of surface parameters was derived from the high-resolution distribution of the main ecosystems of Olson et al. (1983) and from the Earth Radiation Budget Experiment (ERBE) satellite data (Ramanathan et al., 1989), while in the deforestation experiment all points concerned were defined to be of the desert type, and were assigned the appropriate characteristics. The resulting changes in surface parameters are described in Fig. 3. At the grid points 

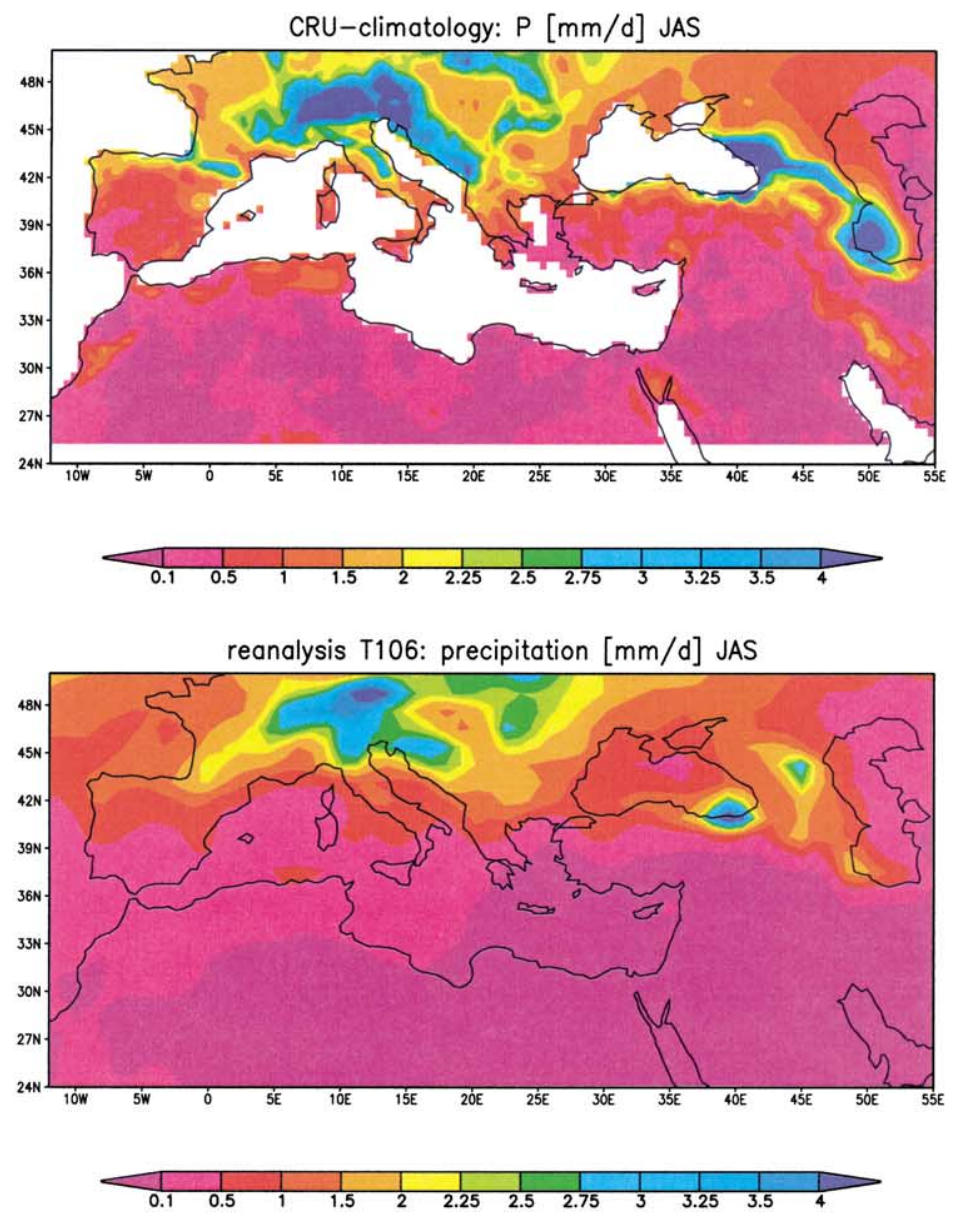

control: precipitation $[\mathrm{mm} / \mathrm{d}] \mathrm{JAS}$
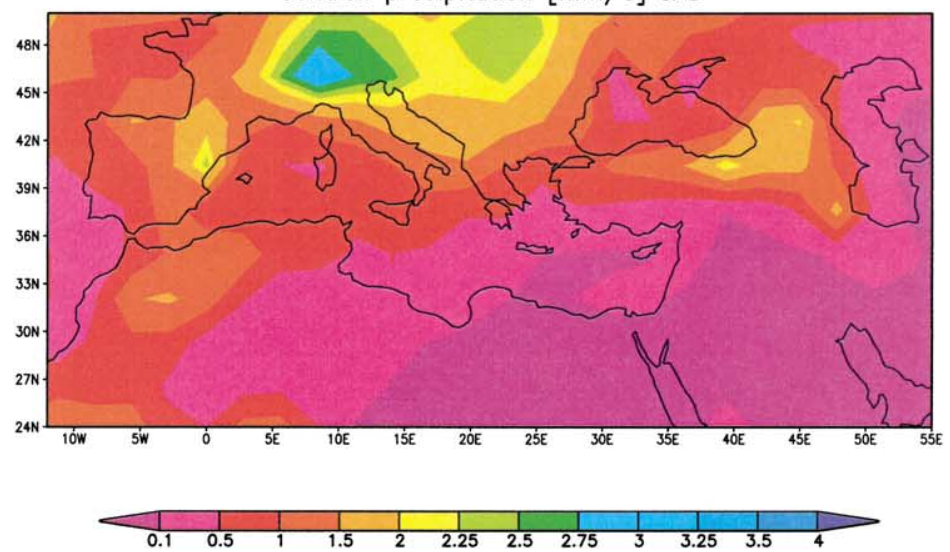

Fig. 2. Precipitation averaged over the summer season (July/August/September) for: (a) the high-resolution climatology (1961-1990) of Hulme et al. (1995), (b) the ECMWF re-analysis at T106 resolution (1979-1988), (c) the control simulation. 

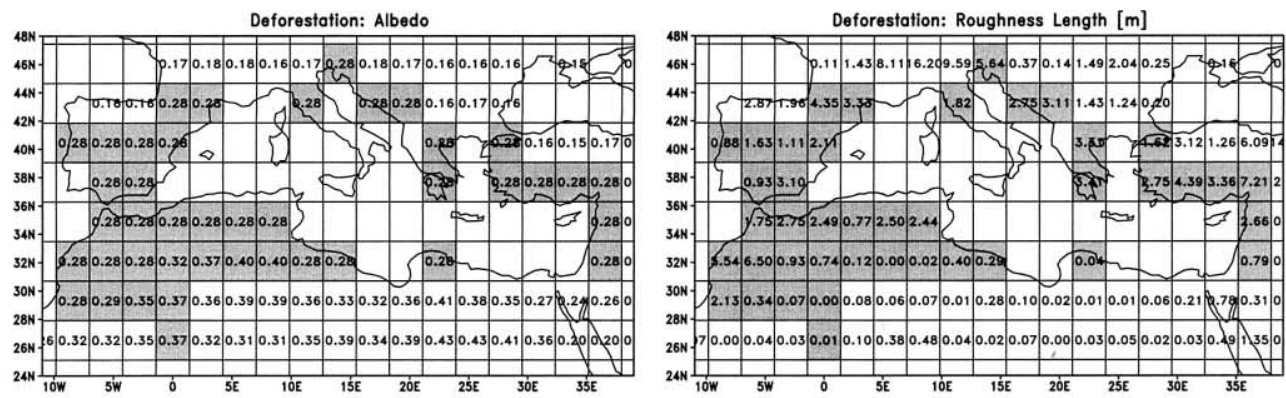

Control: Albedo
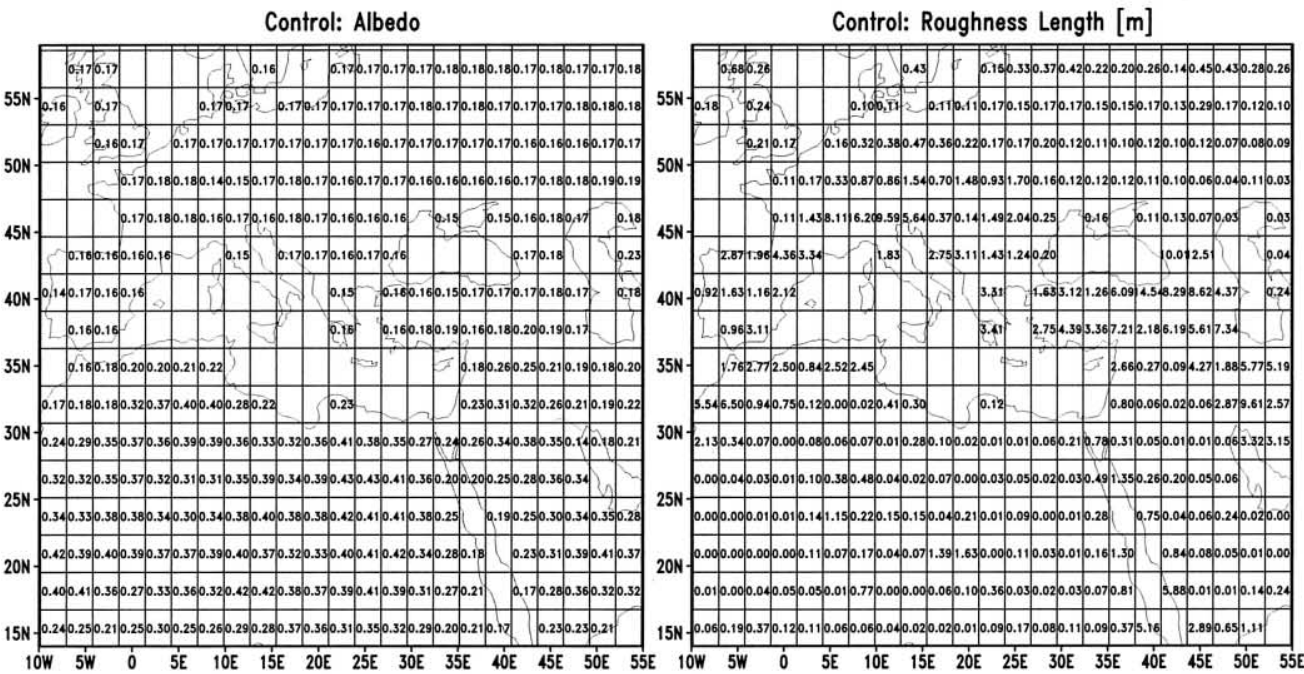

Afforestation: Albedo

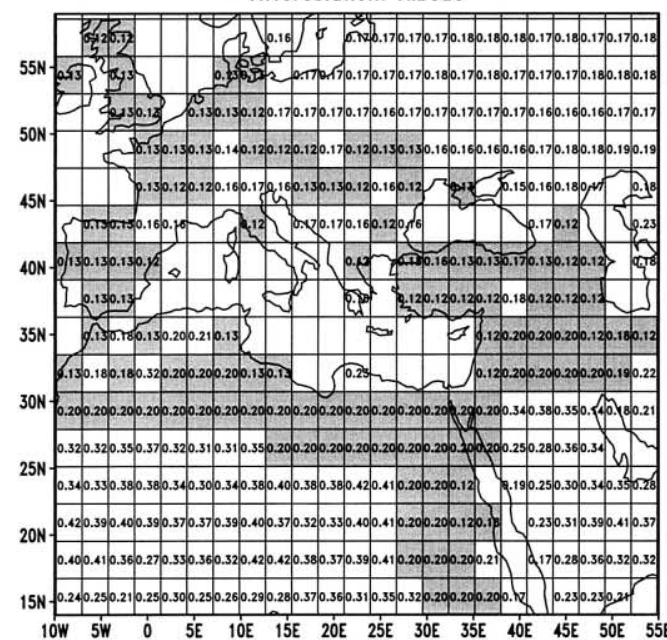

Afforestation: Roughness Length $[\mathrm{m}]$

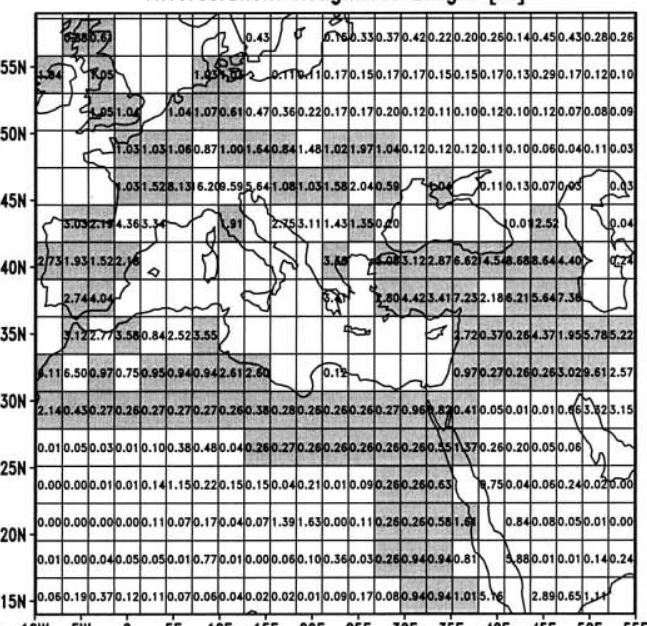

Fig. 3. Distribution of vegetation-related surface boundary conditions (as used in the ECHAM4 atmosphere model; Roeckner et al., 1996) for the control simulation and the deforestation and afforestation experiments. 

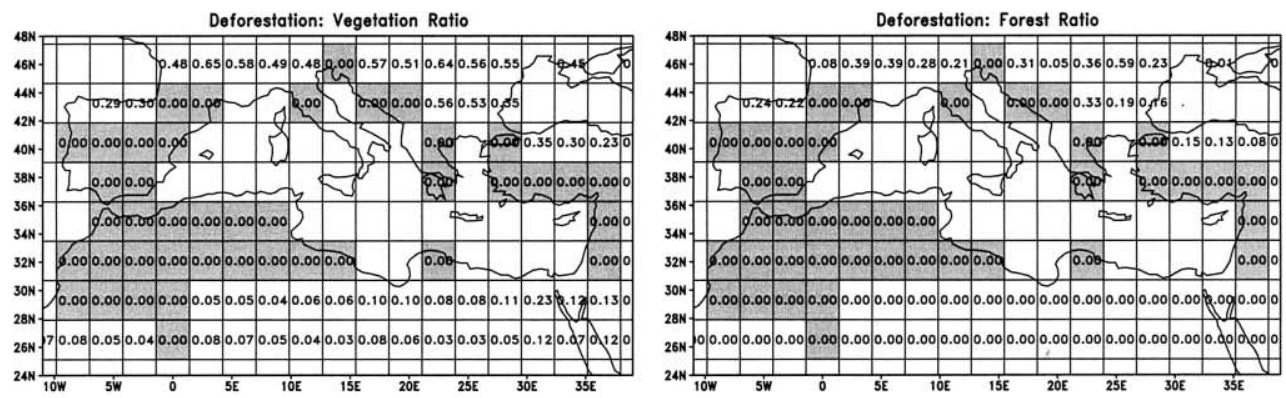

Control: Vegetation Ratio
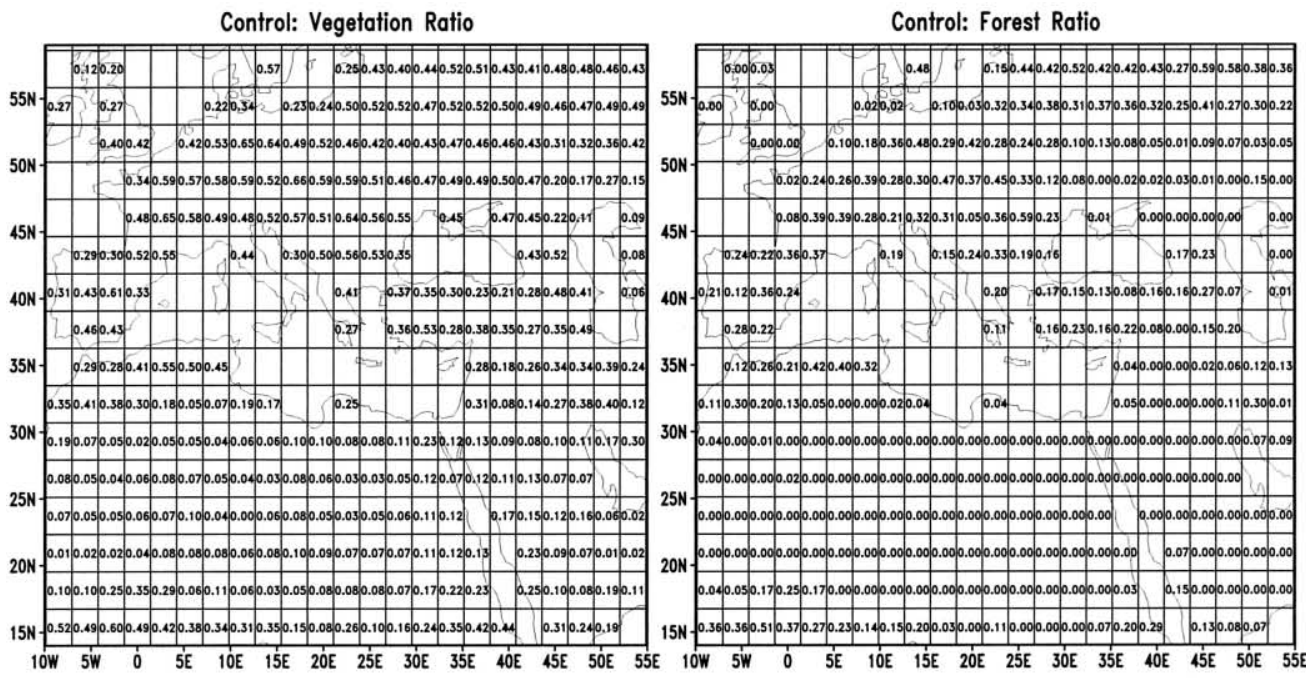

Afforestation: Vegetation Ratio
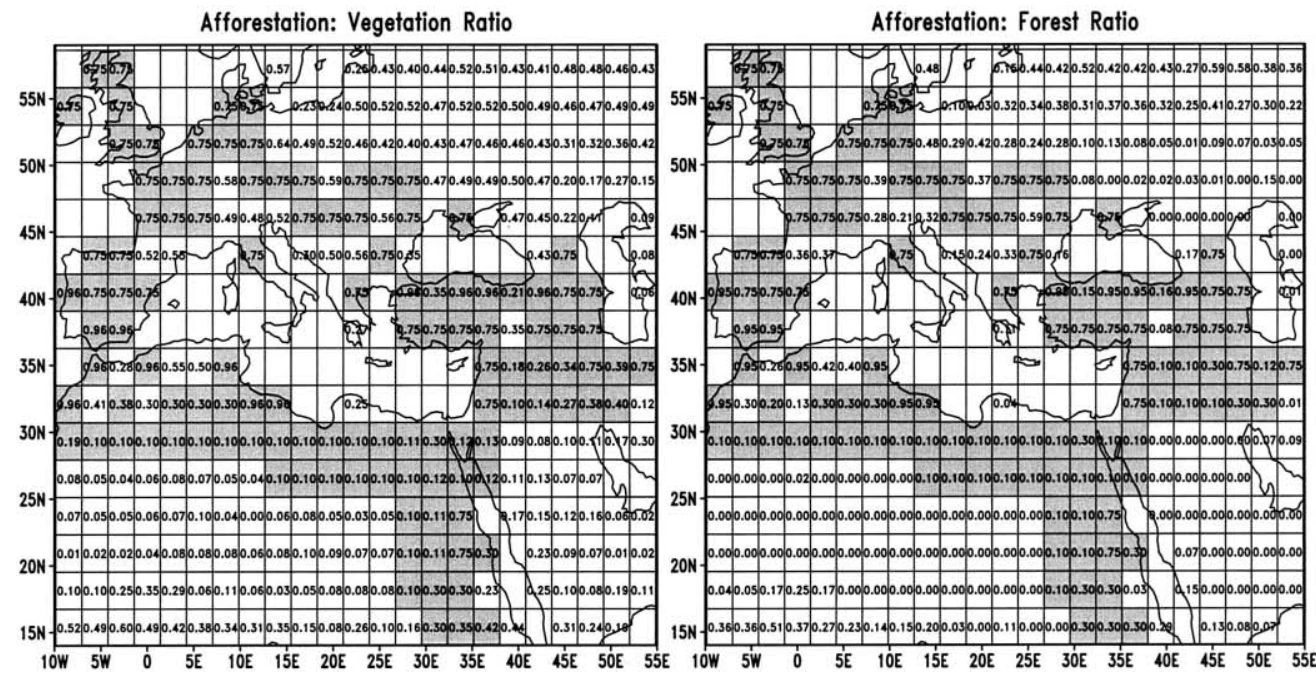

Fig. 3 (continued).

where the original ECHAM4 surface dataset already contained desert characteristics, the original values were kept. A new surface roughness length was computed after vegetation was removed. 

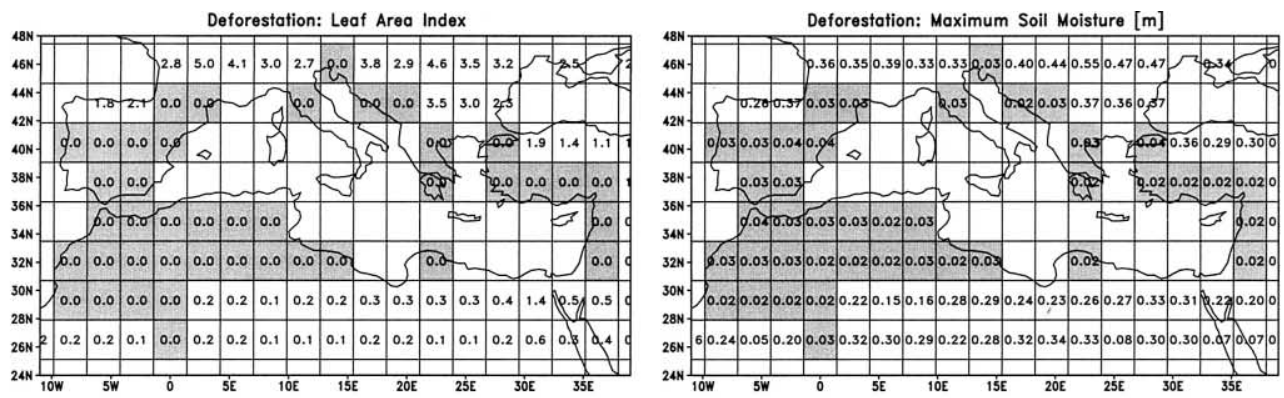

Control: Leaf Area Index
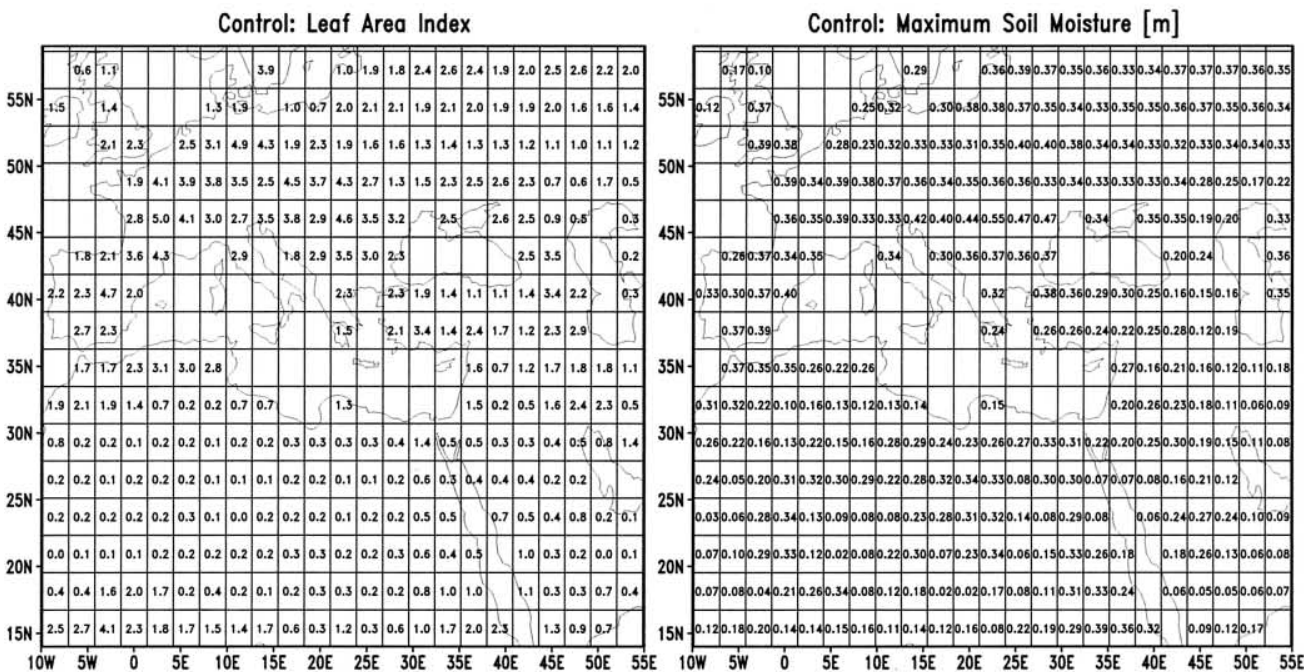

Afforestation: Leaf Area Index
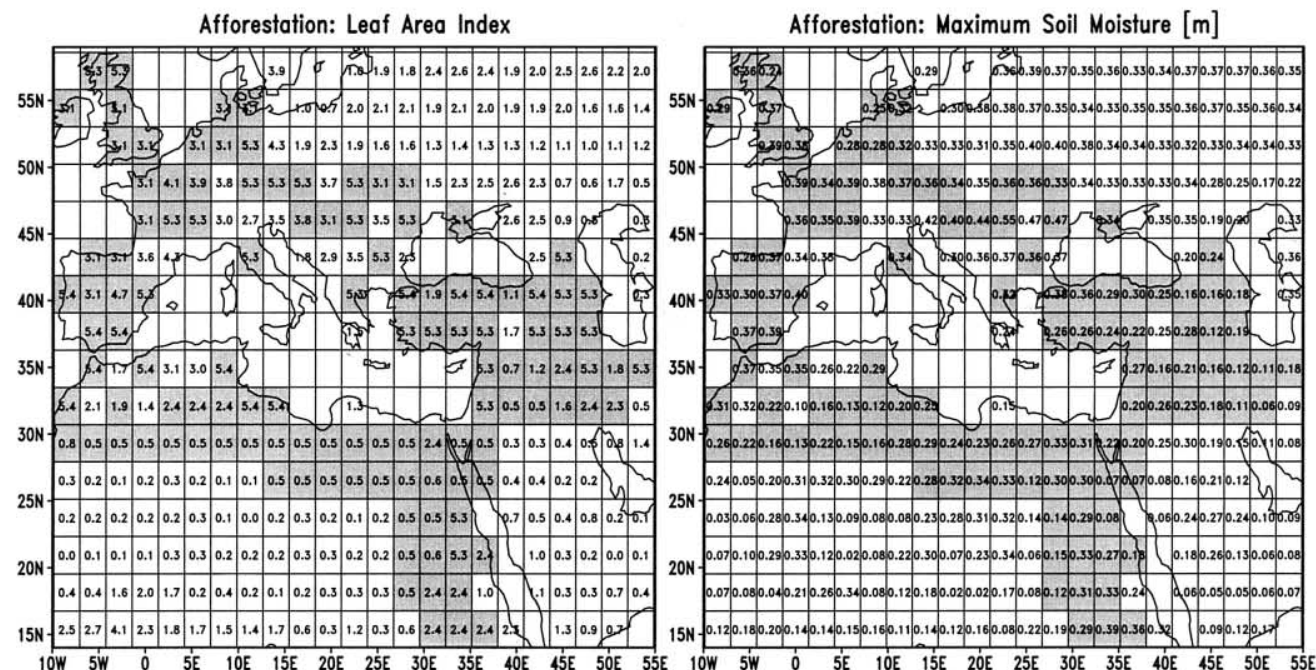

Fig. 3 (continued).

The maximum soil moisture is assumed to depend nearly linearly on rooting depth (Patterson, 1990).
Erosion and fossilization of soils after deforestation will reduce the maximum soil moisture to even 
lower values for non-vegetated areas than are generally used in the model for bare soil, because the soil characteristics also change. The values in the deforestation simulation are therefore rederived as a function of a fictitious rooting depth of $0.1 \mathrm{~m}$ appropriate for extreme deserts (Rowntree and Dümenil, 1995; Abramopoulos et al., 1988).
With a view to establishing if the model may respond to opposite changes in a consistent way, an afforestation experiment was also performed. Here, the vegetation was increased to the amount present during the Roman classical period in the first century B.C. These changes affect an area from the British Isles to the Nile (Fig. 3) and have a different regional

\section{total precipitation $[\mathrm{mm} / \mathrm{d}]$ Difference July 02-05}
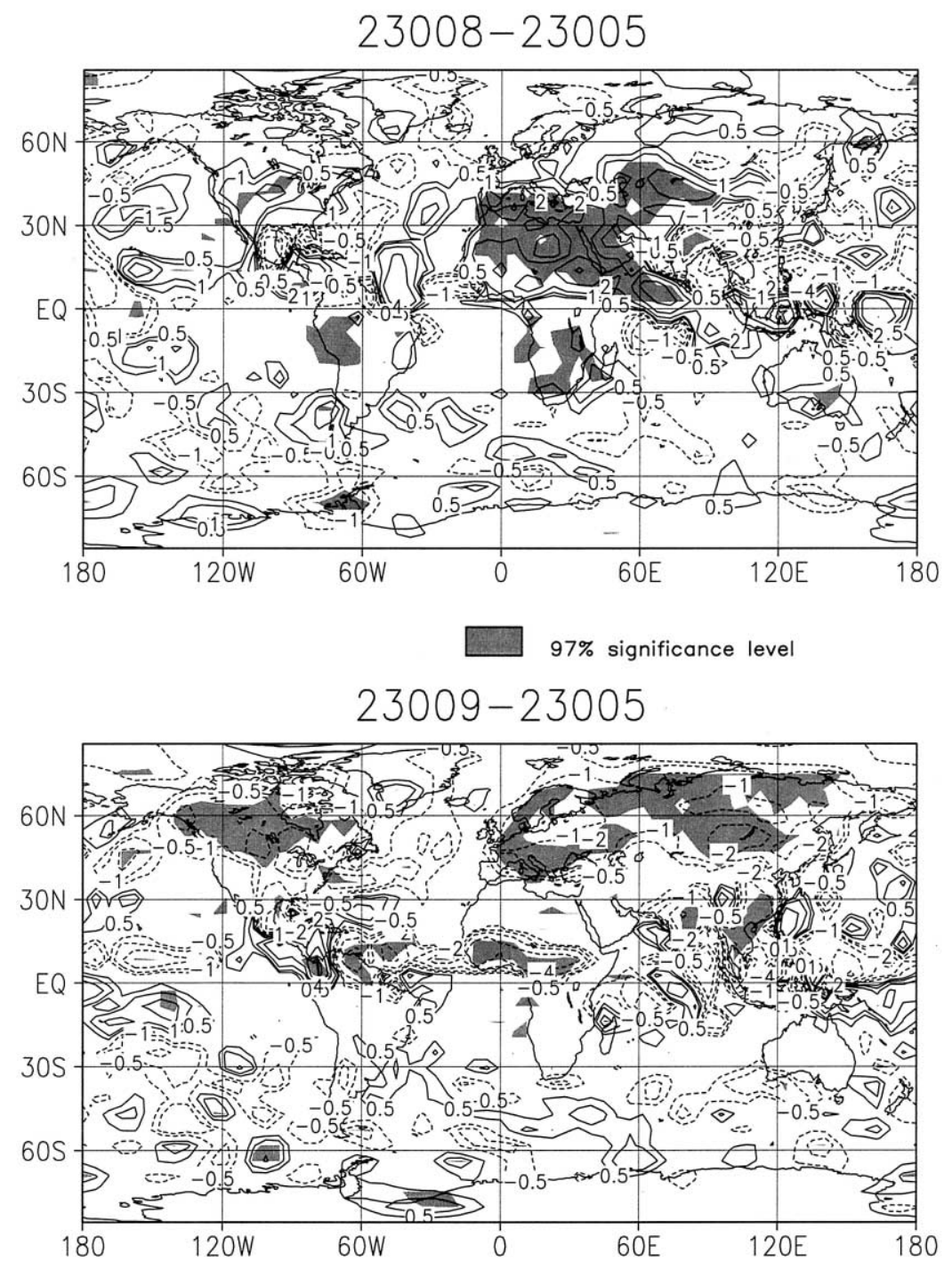

Fig. 4. Difference between a potential evaporation experiment (irrigated continents) and a control simulation using the MPI model at T21 resolution, averaged over 5 years for July mean precipitation (top) and for the difference between a no-land-surface-evaporation experiment (desert continents) and the control simulation (bottom). Solid lines indicate positive differences, dashed lines indicate negative differences. Shading indicates that the differences are significant at the $97 \%$ level of a Student's $t$-test. 
extent than in the deforestation scenario because here a well-documented dataset is available. This dataset was derived from pollen analysis (Huntley and Birks, 1983; Huntley and Webb, 1988) and was converted to the appropriate biome types by Reale and Dirmeyer (2000). A similar (but summer-only) experiment with this dataset was made by Reale and Shukla (2000) with the COLA GCM at a higher resolution than used in this study, and in which the SSiB biosphere model (Xue et al., 1991) was implemented.

\subsection{General land surface sensitivity of the MPI model}

The potential for atmospheric and hydrological changes induced from modifications of the lower boundary conditions is large. Experience over the last decade has, however, illustrated that different GCM experiments show a different sensitivity to changes of the evapotranspiration, for example. In Fig. 4, this sensitivity is shown for a member of the Max-Planck-Institute's general circulation model hierarchy at the horizontal resolution of $\mathrm{T} 21$, which is comparable to the one used in the study by Shukla and Mintz (1982) for summer only simulations. Here, the MPI model was, however, integrated for five full annual cycles. Results shown in Fig. 4 describe the MPI model's response of July precipitation to these authors' specification of "irrigated continents", i.e. the specification of potential evaporation at all land points, and a "desert planet" where no evaporation will occur over land during the annual cycle. Compared to their experiments which comprised 60-day forecasts starting from initial conditions in the summer (Shukla and Mintz, 1982), our model's simulated annual cycle shows less sensitivity. This suggests that allowing the variables to run through the sequence of evolution during a full annual cycle may have a decisive impact on the sensitivity to land surface boundary conditions in a particular region, because reservoirs are replenished during the rainy seasons. If regions have characteristics in the present-day climate that are close to the extreme experimental boundary conditions, they stand out as regions where differences are small. For desert continents the precipitation is reduced over land in the equatorial regions and in continental areas of the Northern Hemisphere. For wet soils, a statistically significant amount of local precipitation can form in the subtropics and the adjacent Mediterranean climates despite the large-scale sinking motion in these regions. Analysis of other model variables and at other model levels showed that the bulk of the statistically significant response is confined to the lower troposphere.

\section{Impacts of deforestation and afforestation}

\subsection{Surface energy budget and near surface temper- ature}

The change of vegetation cover in both experimental simulations considered here is much smaller than the modifications applied in the experiments in Fig. 4. The model response is therefore expected to be smaller. The GCM gives a consistent description of changes in the surface budgets for both the deforestation and the afforestation simulations. Modifications of vegetation that are relevant to the hydrological cycle are associated with changes of the latent heat flux, while modifications of the surface albedo result in changes of solar net radiation. In the

Table 1

Summer averages (July/August/September) of the components of the surface energy budget and the 2-m temperature averaged over grid points in the Atlas mountain range for the control simulation and the experiments

\begin{tabular}{|c|c|c|c|}
\hline $\begin{array}{l}\text { Atlas mountain range } \\
\text { in JAS }\end{array}$ & Deforestation & Control & Afforestation \\
\hline $\begin{array}{l}\text { Net solar radiation } \\
{\left[\mathrm{W} \mathrm{m}^{-2}\right]}\end{array}$ & 185.2 & 194.0 & 206.0 \\
\hline $\begin{array}{l}\text { Downward solar } \\
\text { radiation }\left[\mathrm{W} \mathrm{m}^{-2}\right]\end{array}$ & 262.0 & 257.0 & 251.7 \\
\hline $\begin{array}{l}\text { Upward solar } \\
\text { radiation }\left[\mathrm{W} \mathrm{m}^{-2}\right]\end{array}$ & -76.8 & -63.0 & -45.7 \\
\hline $\begin{array}{l}\text { Net thermal } \\
\text { radiation }\left[\mathrm{W} \mathrm{m}^{-2}\right]\end{array}$ & -97.5 & -95.2 & -96.1 \\
\hline $\begin{array}{l}\text { Downward thermal } \\
\text { radiation }\left[\mathrm{W} \mathrm{m} \mathrm{m}^{-2}\right]\end{array}$ & 378.3 & 381.5 & 386.0 \\
\hline $\begin{array}{l}\text { Upward thermal } \\
\text { radiation }\left[\mathrm{W} \mathrm{m}^{-2}\right]\end{array}$ & -475.8 & -476.7 & -482.0 \\
\hline $\begin{array}{l}\text { Latent heat flux } \\
{\left[\mathrm{W} \mathrm{m}^{-2}\right]}\end{array}$ & -11.1 & -23.4 & -24.4 \\
\hline $\begin{array}{l}\text { Sensible heat flux } \\
{\left[\mathrm{W} \mathrm{m}^{-2}\right]}\end{array}$ & -45.8 & -51.3 & -58.2 \\
\hline $\begin{array}{l}\text { 2-m temperature } \\
{\left[{ }^{\circ} \mathrm{C}\right]}\end{array}$ & 29.0 & 29.2 & 30.2 \\
\hline
\end{tabular}


Mediterranean region, the components of the surface energy budgets (Table 1 for a representative example from the Atlas mountain range) are in general as follows: The turbulent fluxes of momentum, sensible and latent heat are generally decreased for the de- forestation experiment as the roughness length is reduced. The decrease in evaporation due to the reduced vegetation cover and the changed soil conditions results in a significantly decreased latent heat flux, which should be compensated by an increase in

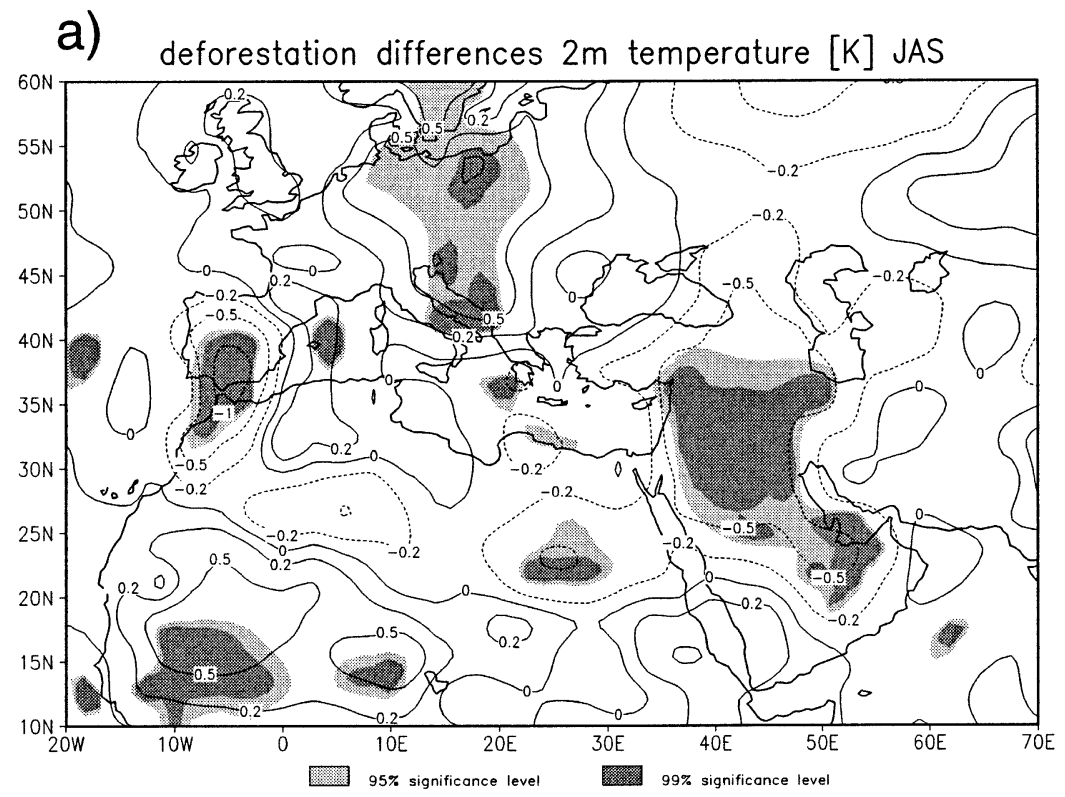

b) afforestation differences $2 m$ temperature [K] JAS

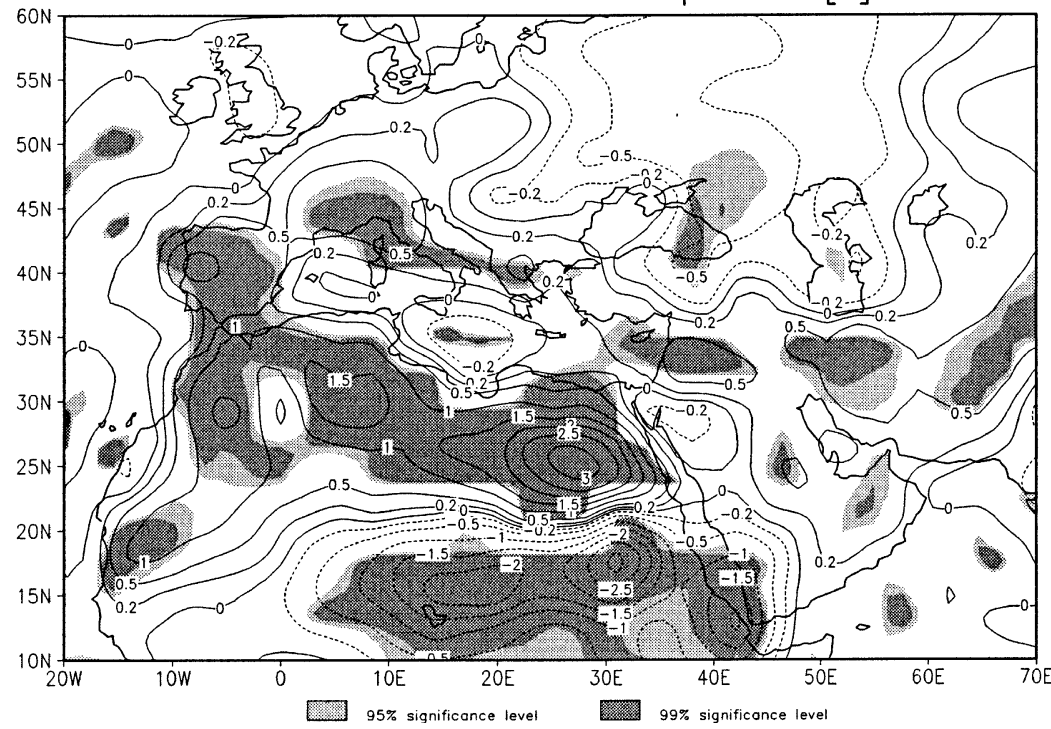

Fig. 5. Differences between the experiments and the control of the summer (July/August/September) average 2-m temperature for: (a) deforestation minus control, (b) afforestation minus control. Light shading indicates significance in a Student's $t$-test at the 95\% level, dark shading at the $99 \%$ level. 
sensible heat flux. As the surface albedo is increased at the same time, the input from net solar radiation at the surface is, however, reduced. This results in less sensible heat flux and, as a consequence, a small decrease in near surface temperature, so that the thermal radiation at the surface does not change much. The cooler and drier surface reduces convection, which suppresses locally produced precipitation. Afforestation generally acts in the opposite way.

The regional pattern of differences in the $2-\mathrm{m}$ temperature averaged over the summer months of the control simulation and the experiments is given in Fig. 5. There are no significant global scale impacts of the changes in Mediterranean vegetation on the dynamics and the hydrological cycle outside the Sahara (not shown).

In both the deforestation and the afforestation cases, the regional pattern of the response is not uniform over the Mediterranean and the surrounding regions. The changes induced by the deforestation or afforestation is due to local changes of the surface parameters as given in Fig. 3, whereas there are no significant changes in the cloud fields. In the north of the area under consideration, we find two limitations: first, the meteorological conditions are highly variable during the wintertime. This may cause a highly irregular pattern of surface conditions trailing from the early spring into the summer. Results in these regions are therefore expected to be less consistent. Second, the horizontal model resolution is too coarse to allow firm conclusions about small-scale remote differences in a highly heterogeneous region.

In the deforestation case colder temperatures are found in the region of the Iberian peninsula, northern Africa and the Middle East, while the differences in the Adriatic are positive. A significant response to the modification of land-surface characteristics is mainly found on the regional scale in the vicinity of the grid points where changes were made. The differences reach a maximum of $1^{\circ} \mathrm{C}$ and are therefore of the order of $20 \%$ of the projected impact of the additional so-called greenhouse effect in that region for doubling of $\mathrm{CO}_{2}$. In the afforestation case, the differences are generally of the opposite sign and are statistically significant in the Mediterranean. Significant changes occur in the Sahara, where the anomalies are very similar to the patterns found by Reale and Shukla (2000) in their (higher resolution) afforestation experiment for an ensemble of summer integrations.

The annual cycle of near-surface temperature is shown in Fig. 6 in terms of the differences between the 10-year afforestation or deforestation experiments and the 25-year control simulation averaged over all land points that were modified in the experiments. For deforestation, there are fewer grid points than for afforestation, as in the latter case, they also

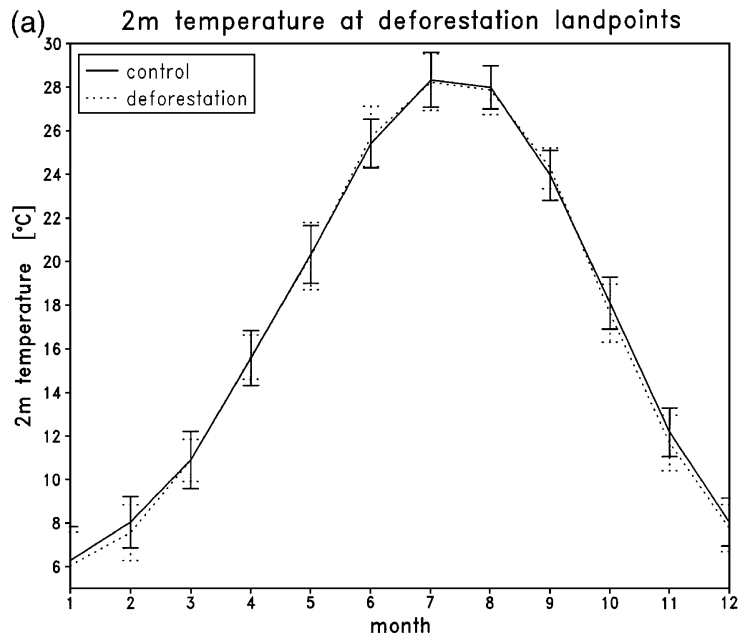

(b) $2 \mathrm{~m}$ temperature at afforestation landpoints

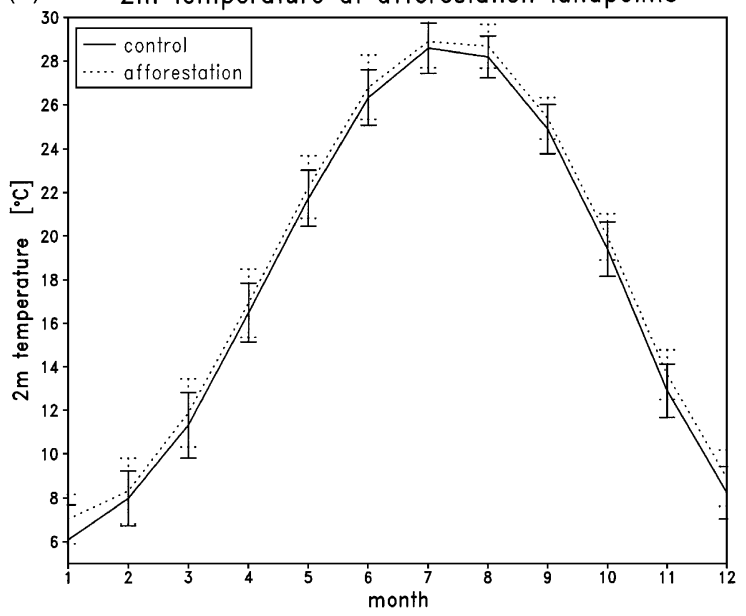

Fig. 6. The seasonal cycle of monthly averaged 2-m-temperature for: (a) the control simulation and the deforestation experiment, (b) the control and the afforestation experiment. Bars indicate the interannual variability as represented in the control simulation and the experiments (all using climatological sea surface temperatures). 

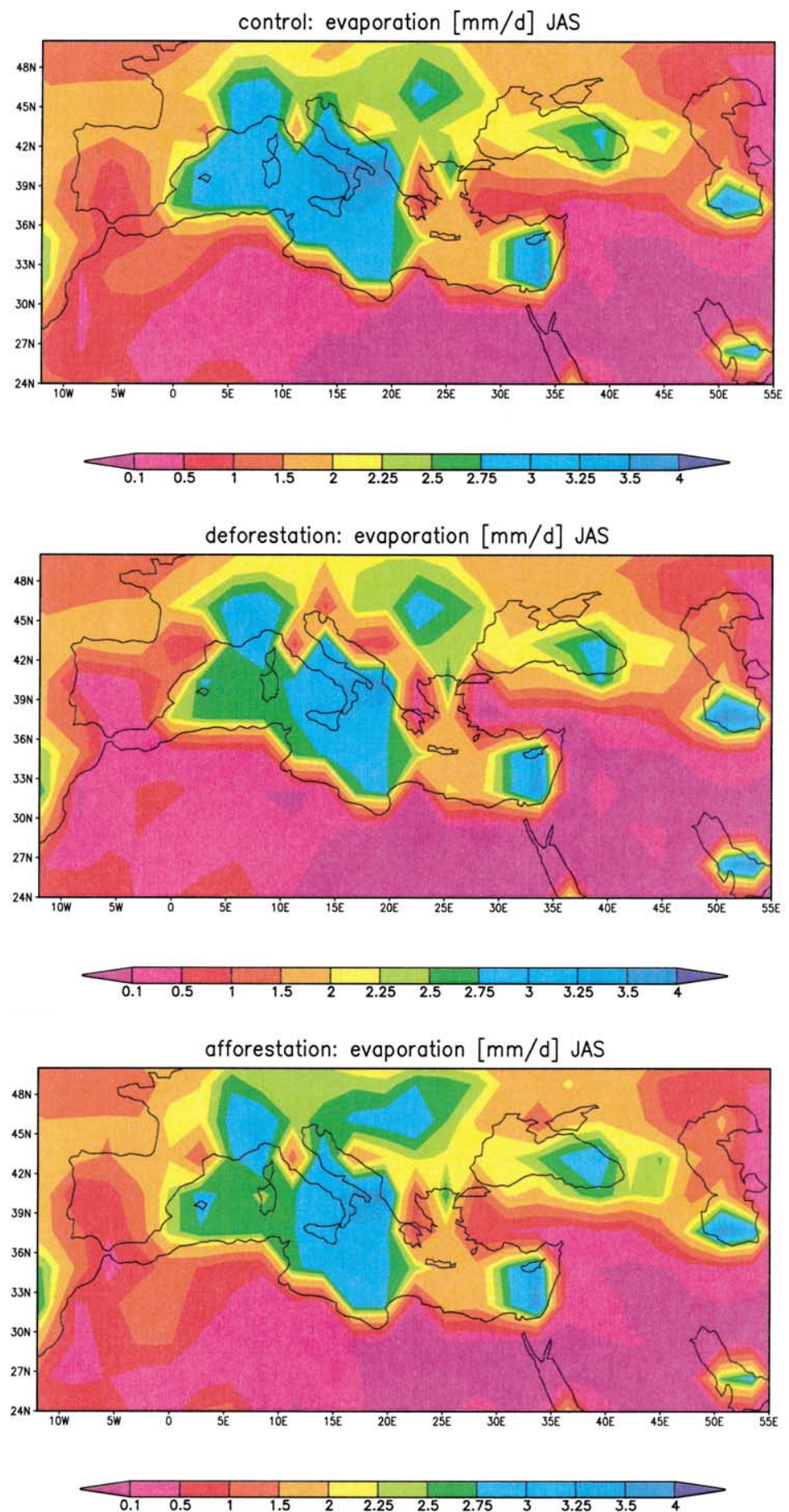

Fig. 7. Evaporation averaged over the summer season (July/August/September) for: (a) the control simulation, (b) the deforestation experiment, (c) the afforestation experiment. 
comprise points at higher latitudes to the north of $40^{\circ} \mathrm{N}$ where almost no changes occur, and along the Nile valley (Fig. 4). Fig. 6 shows an increase in temperatures for all months of the year. This is consistent with the results shown in Table 1.

\subsection{The hydrological cycle}

Due to their critical importance for water resources in the region and the unique capability of ECHAM4 to simulate surface runoff from infiltration excess and drainage, we will pay particular attention to the modification of the components of the hydrological cycle due to deforestation and afforestation in the following. This will be limited to a regional analysis. Further details for sub-regions of the Mediterranean are given by Ließ and Dümenil (1999).

\subsubsection{Evaporation}

The most immediate response to vegetation changes is found in the evaporation. Deforestation generally reduces the evaporation in the summer (Fig. 7), where evaporation is already low. Such regions are the Pyrenees and the whole Iberian peninsula, the Balkan coast, Greece, Turkey and the Middle East. Especially over the Iberian peninsula, a distinct decrease of evaporation is caused by deforestation and an increase is found following afforestation. Changes in northern Africa are restricted to the western parts of the Mediterranean coast, in particular the Atlas mountains. In the control simulation, evaporation is at a maximum in July in this region due to the erroneously high precipitation simulated by the model as discussed above. When the vegetation is removed, evaporation is reduced. In general, the region north of $45^{\circ} \mathrm{N}$ shows a less consistent response due to the dominance of the mid-latitude flow.

In the afforestation case, evaporation increases in the Pyrenees, while evaporation in the Atlas mountain range is hardly affected because the experimental changes applied here are relatively smaller. Large differences also occur over modified land points in the corridor between the Black Sea and Caspian Sea. In the annual cycle (Fig. 8), there is a clear difference in the evaporation between the deforestation and afforestation cases, with the former showing a major decrease in the summer months and the latter a smaller but persistent increase throughout the year.
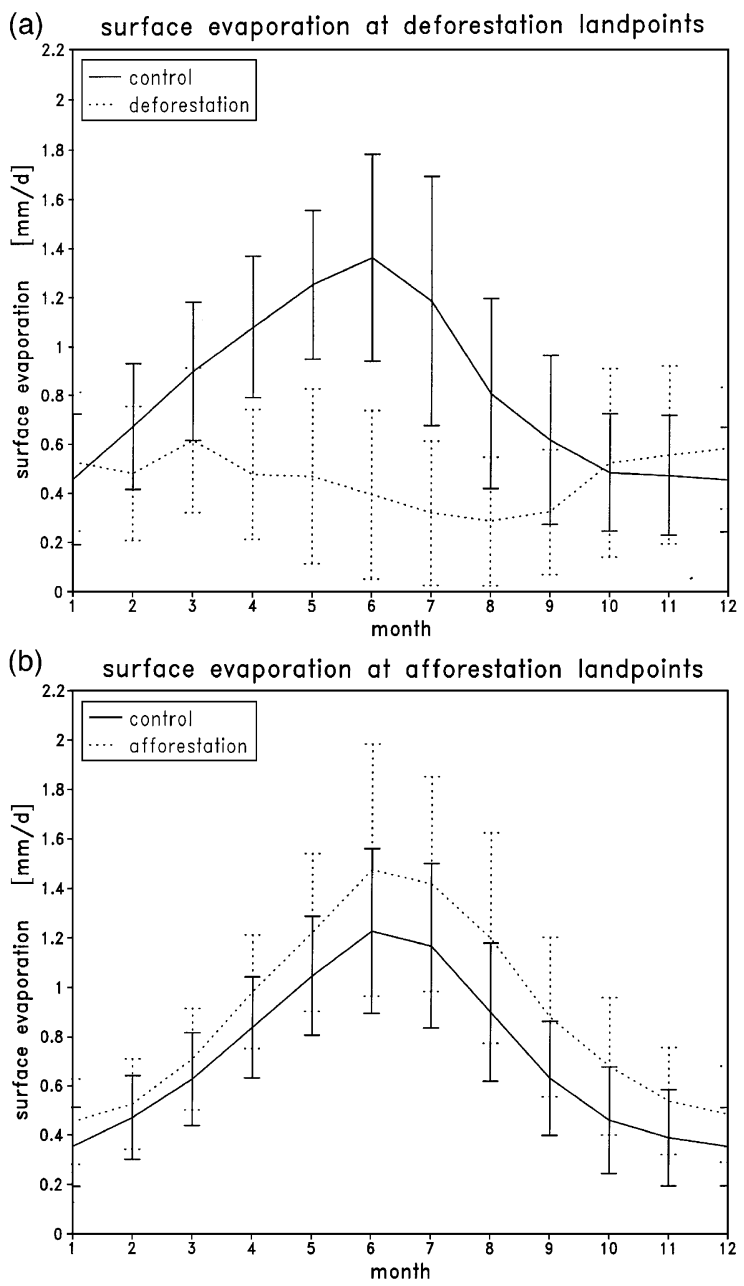

Fig. 8. As in Fig. 6 but for evaporation.

\subsubsection{Precipitation}

While the Mediterranean region is generally classified as a winter-rainfall climatic regime (Köppen, 1931), it shows a large heterogeneity of climatic flows and conditions mainly due to the orographic structure of the terrain. In each of the sub-regions, the effects of deforestation and afforestation will therefore be somewhat different. There is also an interaction with model systematic errors that have a regional structure.

The regional patterns of the precipitation change during the summer months are shown in Fig. 9. In general, the afforestation and deforestation experiments change the precipitation over the Mediter- 
a) deforestation differences total precipitation $[\mathrm{mm} / \mathrm{d}] \mathrm{JAS}$

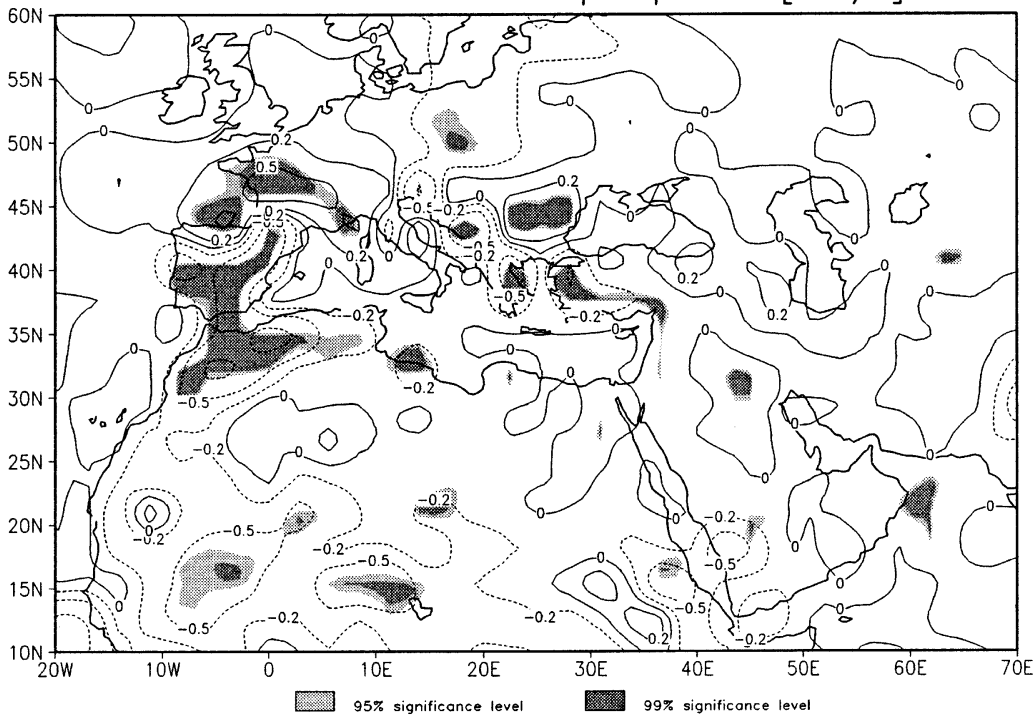

b) afforestation differences total precipitation $[\mathrm{mm} / \mathrm{d}] \mathrm{JAS}$

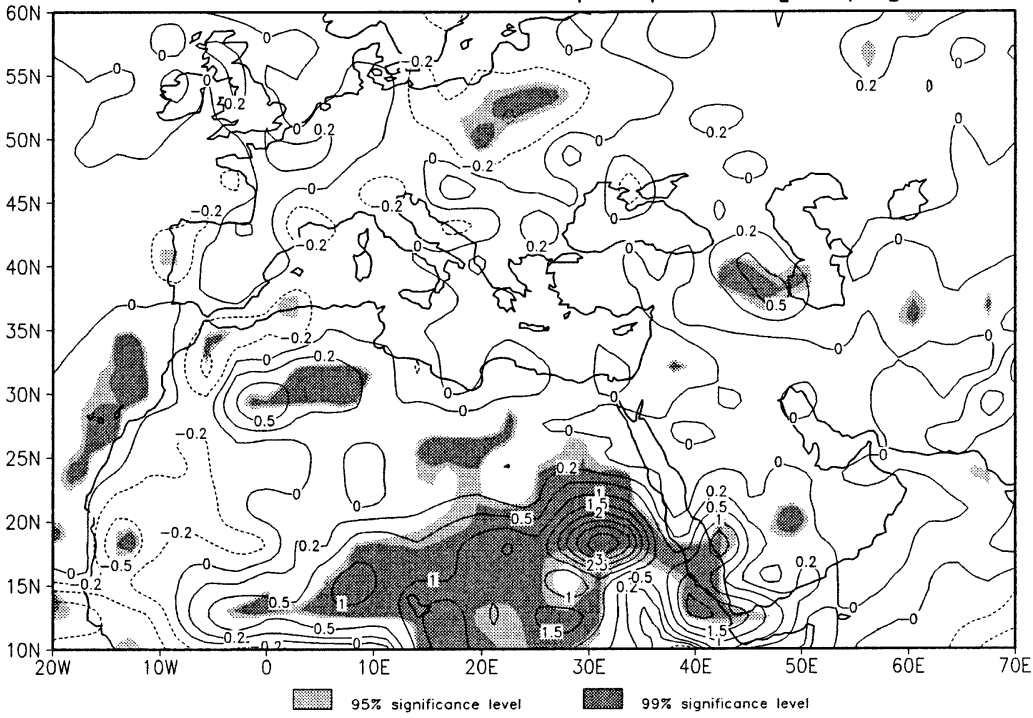

Fig. 9. As in Fig. 5 but for precipitation.

ranean region in opposite ways. The strongest decrease in precipitation due to deforestation is found in the Atlas mountain range. In the European part of the region, the greatest decrease occurs over the Iberian peninsula and along the Balkan coast. All of these differences are significant. In the afforestation case, the simulated response in the Mediterranean region is smaller and of little statistical significance.

The annual cycle of monthly mean changes of simulated precipitation is shown in Fig. 10. Each time series is an average over all land points where land surface characteristics were modified. Although 

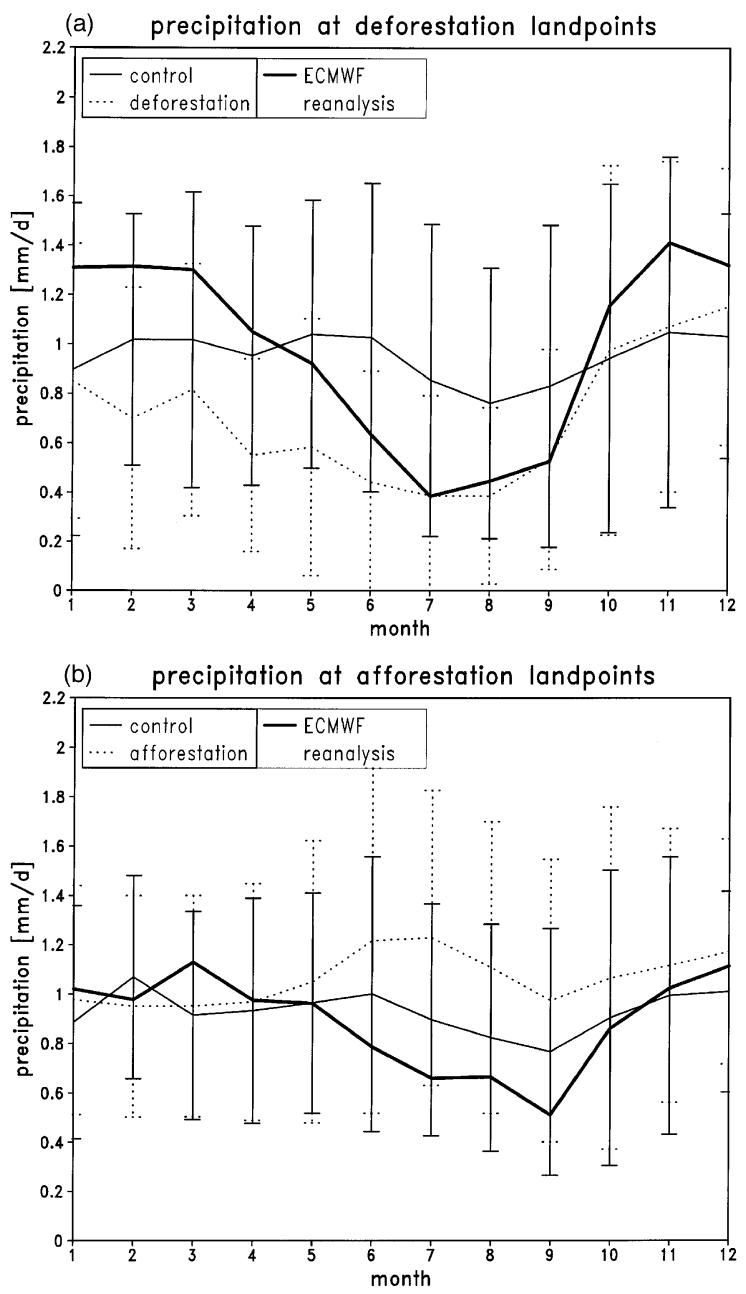

Fig. 10. As in Fig. 6 but for precipitation.

the ECHAM4 model's simulated precipitation has systematic errors with respect to the observed (see Fig. 2), there is a predominant decrease of summer precipitation in the deforested case and a smaller but persistent increase of precipitation throughout the year in the afforested case.

The erroneously large rainfall in the summer is due to a few land points in the Atlas mountain range in northern Africa. Here, a large amount of water is stored in the interception reservoirs of the vegetation and is re-evaporated later during the annual cycle. This creates local rainfall that is unrealistic. The large amount of vegetation at several grid points in the ECHAM4 model in North Africa is not supported by the latest state-of-the-art vegetation datasets obtained from satellite measurements (Hagemann et al., 1999). An indication of what effects a smaller vegetation fraction would have is found in the deforestation experiment, where the erroneously high roughness of the terrain and the recycling of water in this region is reduced and leads to better agreement with observed precipitation.

In the afforestation experiment, the region where changes were made to the land surface characteristics is different, and also comprises points in mid-latitudes (Fig. 3). This is reflected in a less pronounced range of the observed annual cycle of precipitation (Fig. 10) of the average of all modified land points. Precipitation increases in both winter and in summer, but larger differences occur in the summer. In the Mediterranean the response of the hydrological cycle is in general opposite to that of the deforestation experiment. The regional impact is less pronounced (Fig. 9), because the applied changes are more moderate (Fig. 3).

In the afforestation experiment, precipitation anomalies occur in the eastern central part of the Sahara (Fig. 9). In the afforestation experiment a positive significant anomaly occurs near and downstream from the modifications in the Nile valley. Due to the more restricted mask of changed land points, this anomaly has no counterpart in the deforestation experiment. The anomaly patterns in the Sahara agree with those found by Reale and Shukla (2000) and those in Fig. 5. They are consistent with the arguments of Charney (1975) and Charney et al. (1977). Due to the moistening of the soil and the resulting change of the Bowen ration the surface temperature in this region decreases (Fig. 5).

\subsubsection{Surface runoff}

The model-simulated surface runoff and drainage for the deforestation experiment are shown in Fig. 11 , but there are no observations for either of these quantities. The model-simulated runoff and drainage generally follow the precipitation, and can occur before the soil water reservoir reaches saturation (Dümenil and Todini, 1992). Runoff from thunderstorm events in the summer is not represented in the model due to its coarse resolution. Therefore, the 

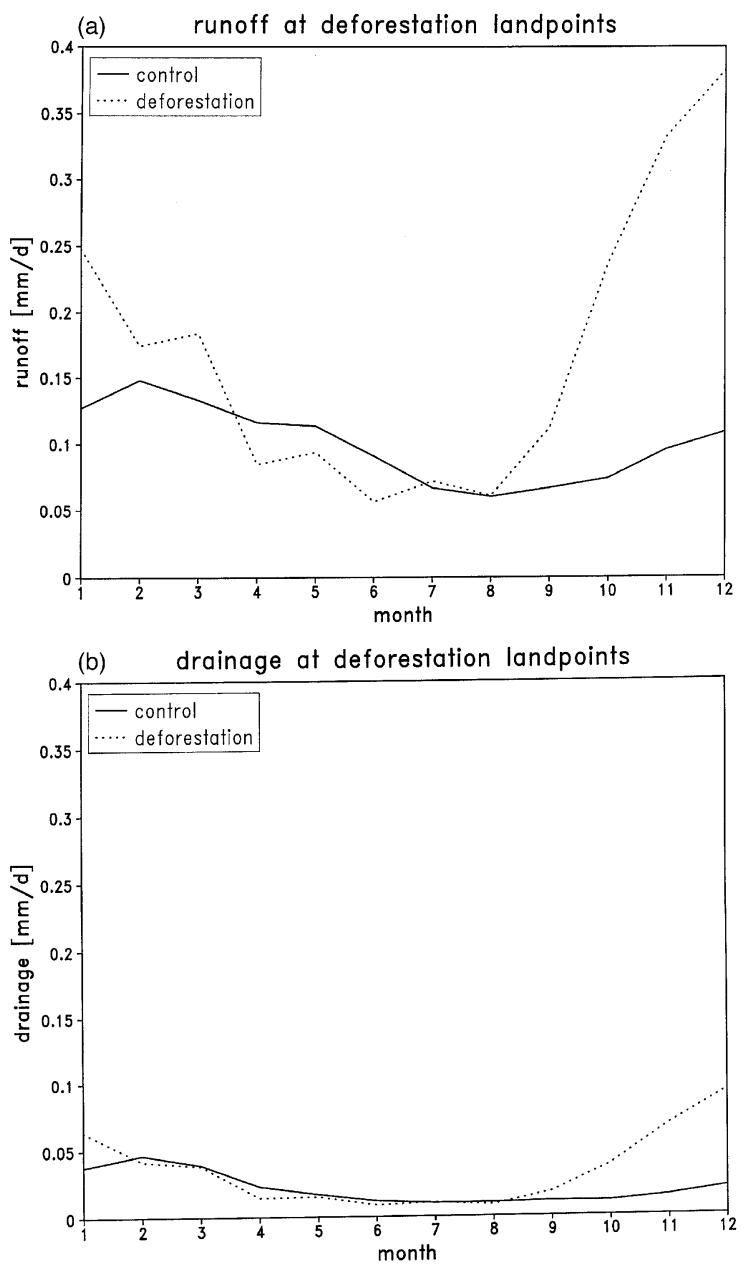

Fig. 11. The seasonal cycle of monthly mean values of (a) surface runoff and (b) drainage for the deforestation and control simulations averaged over deforested land points.

strongest impact on runoff occurs in winter, when precipitation exceeds evaporation, because soil water reservoirs have been set to minimum values in the experiment (cf. Fig. 3) and runoff can occur more frequently. This result is, of course, model-dependent and has to be seen against the background of the systematic model errors discussed above. The drainage (Fig. 11b) shows similar behaviour, but the changes are smaller.

The changes of surface runoff and drainage caused by afforestation (not shown) are generally smaller than those caused by deforestation because of the relatively small increase in maximum soil moisture as compared to the control simulation.

\section{Conclusions}

The general circulation model ECHAM4 was used to identify the sensitivity of the local and global climate to desertification and afforestation in the Mediterranean. The deforestation scenario represents an extreme desert, which would be the worst case scenario for this region. The changes in the afforestation experiment are spread over a relatively larger area according to the pattern of the vegetation cover 2000 years before present as given by Reale and Shukla (2000), and include some points at mid-latitudes.

After deforestation, evaporation shows the largest significant response in terms of a decrease, while the local climate is subjected to a slight cooling at the surface. Locally produced summer precipitation is reduced consistent with less evapotranspiration and less bare soil evaporation, but the results vary regionally. In general, the results of the afforestation experiment are opposite in sign to those found in the deforestation case, but the response is smaller because the modifications are smaller than in the deforestation case. The response in the Sahara in the case of afforestation is very similar to the response found by Reale and Shukla (2000) and is statistically significant.

In general, our model results agree with the results of Reale and Shukla (2000) indicating that the larger vegetation cover during the Roman Classical Period may have allowed more precipitation to form locally in the summer, and that the vegetation might have been sustained by this precipitation. The model sensitivity also indicates that land use change over the centuries may have had an effect on near surface temperature in some regions of the Mediterranean, which should be taken into account if long-term times series of observations are examined.

The specific parameterization schemes used in our model make the results model-dependent. While the ECHAM4 model at T42 resolution is, in principle, capable of representing an atmospheric circulation resembling the observed, model systematic errors in the winter circulation in the domain of this study 
cause an unrealistically dry climate in the Mediterranean area and too much precipitation in the Atlas mountain region. Nevertheless, the GCM is capable of giving a consistent description of the change of physical processes at the land surface. Both the model-simulated hydrological cycle and surface energy budget are influenced by deforestation or afforestation in a consistent way. The model systematic error of reduced winter precipitation in the Mediterranean makes our results highly model-dependent: If there is less than observed precipitation in the winter, the soil will be too dry in the early spring. This may suppress the local evaporation and evapotranspiration (re-evaporation of rainfall intercepted by the vegetation is not affected, because of small precipitation levels). This may affect the relative importance of the hydrological changes relative to radiation responses driven by albedo change. Since the evaporation and albedo changes tend to exert opposite effects, suppressing one, but not the other, could affect the magnitude or even the sign of the net response.

We should also note that the results of sensitivity tests depend crucially on the climate conditions of the region where they are performed. In experimental deforestation simulations for humid regions such as the tropical rainforests, the response is quite different. There, the surface temperature increases (e.g. Lean et al., 1996) because the reduction of evaporation more than compensates the changes of net solar radiation and a net heating is available for heating the soil. Such results have also been shown to be model-dependent, but it is reassuring to see that the results for Amazonian deforestation found by others were reproduced in a sensitivity experiment with the ECHAM4 model.

In parallel to the present GCM study, a regional study of deforestation in the Mediterranean has been undertaken with the PROMES and HIRHAM regional models (Polcher et al., 1999) in order to study if more realistic levels of internal variability have an influence on the model response. In addition work is in progress to investigate how a more realistic description of the winter circulation would change the response found in the present experiments.

Considering the high sensitivity of the model and its tendency to create self-sustaining conditions as in the Atlas mountain range, it is of utmost importance that the correct vegetation boundary conditions be specified when present-day climate conditions are to be simulated. To minimize unrealistic feedback in the model, new surface parameters derived from satellite data have been specified for future ECHAM and HIRHAM model development in order to represent the local present-day climate more faithfully (Hagemann et al., 1999).

\section{Acknowledgements}

The study presented here is part of the EU-Project "Land-Surface Processes and Climate Response" No. ENV4-CT95-0112-PL950189. We would like to thank Oreste Reale for providing the data set used in the afforestation experiment, Yongkang Xue for providing the soil parameters from SSiB. We thank Lennart Bengtsson and Hartmut Graßl for their support and the staff at MPI for technical assistance and scientific discussions. We are grateful to Richard Betts and an anonymous reviewer for their valuable comments. The re-analyses data were supplied by ECMWF and DWD in cooperation with DKRZ.

\section{References}

Abramopoulos, F., Rosenzweig, C., Choudhury, B., 1988. Improved ground hydrology calculations for global climate models (GCMs): soil water movement and evaporation. J. Clim. 1, 921-941.

Bengtsson, L., Arpe, K., Roeckner, E., Schulzweida, U., 1996. Climate predictability experiments with a general circulation model. Clim. Dyn. 12, 261-278.

Bolle, H.J. et al., 1993. EFEDA: European field experiment in a desertification-threatened area. Ann. Geophys. 11, 173-189.

Charney, J., 1975. Dynamics of deserts and drought in the Sahel. Q. J. R. Meteorol. Soc. 101, 193-202.

Charney, J., Quirk, W.J., Chow, S.H., Kornfield, J., 1977. A comparative study of the effects of albedo change on drought in semi-arid regions. J. Atmos. Sci. 34, 1366-1385.

Dümenil, L., Todini, E., 1992. A rainfall-runoff scheme for use in the Hamburg climate model. In: O'Kane, J.P. (Ed.), Advances in Theoretical Hydrology, vol. 1. Elsevier, Amsterdam, pp. $129-157$

Gash, J.H.C., Nobre, C.A., Roberts, J.M., Victoria, R.L., 1996. An overview of ABRACOS. In: Gash, J.H.C., Nobre, C.A., Roberts, J.M., Victoria, R.L. (Eds.), Amazonian Deforestation and Climate. Wiley, Chichester, UK, pp. 1-15.

Gibson, J.K., Kallberg, P., Uppala, S., Hernandez, A., Nomura, A., Serrano, E., 1997. The ECMWF Re-Analysis (ERA): 1. ERA description. ECMWF Re-Analysis Project Report Series 
No. 1. European Centre for Medium-Range Weather Forecasts, Reading, UK, $71 \mathrm{pp}$.

Hagemann, S., Botzet, M., Dümenil, L., Machenhauer, B., 1999. Derivation of global GCM boundary conditions from $1 \mathrm{~km}$ land use satellite data. Report No. 289, Max-Planck-Institut für Meteorologie, Hamburg, 34 pp.

Hulme, M., Conway, D., Jones, P.D., Barrow, E.M., Jiang, T., Turney, C., 1995. Construction of a 1961-90 European climatology for climate change, modelling and impacts applications. Int. J. Climatol. 15, 1333-1363.

Huntley, B., Birks, H., 1983. An Atlas of Past and Present Pollen Maps for Europe: 0-13,000 Years Ago. Cambridge Univ. Press, Cambridge, 667 pp.

Huntley, B., Webb III, T. (Eds.), 1988. Vegetation History. Handbook of Vegetation Science, vol. 7. Kluwer Academic Publishing, Dordrecht, 803 pp.

IPCC, 1990. Scientific Assessment of Climate Change. Cambridge Univ. Press, Cambridge, UK, 366 pp.

IPCC, 1995. Climate Change 1995-The Science of Climate Change. Cambridge Univ. Press, Cambridge, UK, 572 pp.

Köppen, W., 1931. Grundriss der Klimakunde. Die Klimate der Erde. W. de Gruyter and Co., Berlin, 388 pp.

Lean, J., Bunton, C., Nobre, C., Rowntree, P., 1996. The simulated impact of Amazonian deforestation on climate using measured ABRACOS vegetation characteristics. In: Gash, J., Nobre, C., Roberts, J., Victoria, R. (Eds.), Amazonian Deforestation and Climate. Wiley, Chichester, UK, pp. 549-576.

Ließ, S., Dümenil, L., 1999. The response of ECHAM to the land-surface change. In: Polcher, J. (Ed.), Final Report for EU contract "Land-surface Processes and Climate Response". LMD, Paris, 235 pp.

Olson, J., Watts, J., Allison, L., 1983. Carbon in live vegetation of major world ecosystems. Report ORNL-5862, Oak Ridge National Laboratory, Oak Ridge, TN, 397 pp.
Patterson, K., 1990. Global distributions of total and total-available soil water-holding capacities. Dissertation, Dept. of Geography, University of Delaware, $119 \mathrm{pp}$.

Polcher, J. et al., 1999. Final Report for EU Contract "Land-surface Processes and Climate Response”. LMD, Paris, 235 pp.

Ramanathan, V., Cess, R., Harrison, E., Minis, P., Ahmad, B.B.E., Hartmann, D., 1989. Cloud radiative forcing and climate: results from the Earth Radiation Budget Experiment. Science 243, 57-63.

Reale, O., Dirmeyer, P., 2000. Modeling the effects of vegetation on Mediterranean climate during the Roman Classical Period. Part I: Climate history and model sensitivity. Global and Planetary Change 25 (3-4), 163-184.

Reale, O., Shukla, J., 2000. Modeling the effects of vegetation on Mediterranean climate during the Roman classical period. Part II: Model simulation. Global Planet. Change 25 (3-4), 185214.

Roeckner, E., Arpe, K., Bengtsson, L., Christoph, M., Claussen, M., Dumenil, L., Esch, M., Giorgetta, M., Schlese, U., Schulzweida, U., 1996. The atmospheric general circulation model ECHAM4: Model description and simulation of present-day climate. Report No. 218, Max-Planck-Institut für Meteorologie, Hamburg, 90 pp.

Rother, K., 1993. Der Mittelmeerraum. Teubner Studienbücher der Geographie, Stuttgart, $212 \mathrm{pp}$.

Rowntree, P., Dümenil, L., 1995. Hydrology in climate models and effects on climate. In: Oliver, H., Oliver, S. (Eds.), The Role of Water and the Hydrological Cycle in Global Change. Springer Verlag, Berlin, pp. 59-104.

Shukla, J., Mintz, Y., 1982. Influence of land-surface evapotranspiration on the Earth's climate. Science 215, 1498-1501.

Xue, Y., Sellers, P., Kinter, J., Shukla, J., 1991. A simplified biosphere model for global climate studies. J. Clim. 4, 345360. 